\title{
PENGARUH GREEN MARKETING DAN BRAND IMAGE TERHADAP MINAT BELI AMDK MEREK AQUA DI KALANGAN MAHASISWA S1 FAKULTAS EKONOMI DAN BISNIS UNIVERSITAS MATARAM
}

\author{
Baiq Khaerunnisa ${ }^{1}$ \\ 1 Fakultas Ekonomi dan Bisnis Unram, baiq95@yahoo.com
}

\begin{abstract}
ABSTRAK
Penelitian ini bertujuan untuk mengetahui pengaruh geen marketing dan brand image terhadap minat beli Amdk merek aqua dikalangan mahasiswa S1 Fakultas Ekonomi dan Bisnis Universitas Mataram. Penelitian ini menggunakan dua variabel independen dari Green marketing, yaitu produk, harga, promosi dan tempat. Dan Brand image, yaitu Kesan professional, Kesan modern, Melayani semua segmen, dan perhatian kepada konsumen. Sampel dalam penelitian sebanyak 100 responden dengan menggunakan accidental sampling. Metode analisis data menggunakan metode kuantitatif dan dianalisis menggunakan analisis regresi linier berganda. Hasil dari penelitian ini adalah green marketing berpengaruh positif terhadap minat beli. sedangkan Brand image berpengaruh negative terhadap minat beli.
\end{abstract}

Kata Kunci: Green marketing, Brand Image, Minat beli.

\begin{abstract}
This study aims to determine the effect of geen marketing and brand image on buying interest of mineral water brand of Aqua among undergraduate degree students of the Faculty of Economics and Business, University of Mataram. This study uses two independent variables; Green Marketing, namely products, prices, promotions and places, and Brand Image, namely professional impression, modern impression, serving all segments and attention to consumers. The sample in the study were 100 respondents using accidental sampling. The method of data analysis uses quantitative methods and analyzed using multiple linear regression analysis. The results of this study are Green Marketing has a positive effect on buying interest. while Brand Image has a negative effect on buying interest.
\end{abstract}

Keywords: Green Marketing, Brand Image, Buying Interest.

\section{PENDAHULUAN}

\section{Latar Belakang}

Istilah green marketing muncul kepermukaan sebagai reaksi dari paramarketer untuk peduli lingkungan. Green marketing kemudian menjadi alternatif strategi yang tidak hanya membantu image perusahaan, tetapi juga memberi value terhadap bisnis perusahaan. Namun yang menjadi ketakutan marketer untuk terjun ke dunia green marketing karena paramarketer merasakan bahwa target pasar mereka belum berorientasi kepada lingkungan hidup. Itulah sebabnya pertumbuhan produk-produk yang ramah lingkungan terkesan lambat. Kesadaran perusahaan-perusahaanterhadap lingkungan mulai tumbuh sejak dulu, hal ini dibuktikandengan aktivitasmarketing beberapa tahun yang lalu secara sukses menandakan isu-isu hijau melalui simbol dan 
desain hijau dan kampanye iklan secara reguler menggambarkan citra alam, hidup bersih, dan lingkungan harmonis pada sejumlah barang konsumen.

Pendekatan pemasaran hijau (green marketing approach) pada area produk diyakini dapat meningkatkan integrasi dari isu lingkungan pada seluruh aspek dari aktivitas perusahaan, mulai dari formulasi strategi, perencanaan, penyusunan, sampai produksi dan penyaluran atau distribusi dengan pelanggan. Green marketing sebenarnya merupakan deskripsi sebagai usaha organisasi atau perusahaan mendesign, promosi, harga dan distribusi produk-produk yang tidak merugikan lingkungan.Merk merupakan salah satu indikator identitas produsen, dari sini lah para konsumen mengingat suatu produk. Fenomena yang terjadi di masyarakat berkaitan dengan Aqua adalah masyarat sudah terbiasa menggunkan AMDK ini sejak tahun 1970, sehingga secara tak sadar, konsumen akan langsung menyebut merk Aqua jika membeli air mineral di warung. Dengan banyaknya pesaing saat ini tak membuat Aqua gentar, justru membuktikan produk AMDK tertua ini masih jaya hingga saat ini. Berikut tabel Top Index.

Tabel 1. Top Brand Indeks (TBI) Katagori AMDK Tahun 2015
\begin{tabular}{|c|c|c|}
\hline No & Merek & TBI \\
\hline 1 & AQUA & 75,9 \\
\hline 2 & Club & 5,0 \\
\hline 3 & VIT & 2,6 \\
\hline 4 & Ades & 2,6 \\
\hline
\end{tabular}

Sumber: $\underline{w w w . t o p b r a n d-a w a r d . c o m}$

Aqua merupakan salah satu produk yang memiliki citra merk (brand image) yang kuat di kalangan masyakarat, hal ini juga disebabkan Aqua merupakan produk AMDK pertama di Indonesia. Sejak tahun 1973 pertama kali produk ini di perkenalkan mungkin masyarakat masih sedikit yang mengetahui. Air minum merupakan salah satu kebutuhan primer yang harus dipenuhi oleh konsumen, mengingat ada jumlah minimal pemenuhan kebutuhan air minum untuk tubuh perhari. Membuat pelaku pasar memanfaatkan peluang ini untuk memproduksi Air Mineral Dalam Kemasan (AMDK) dengan berbagai keunggulan. Terbukti saat ini telah banyak Perusahaan AMDK yang berdiri dengan mengusung merek dagang nya dengan berbagai macam logo dan warna agar menarik minat konsumen.Saat ini banyak di jumpai merek-merek AMDK yang telah banyak beredar seperti di Supermarket,Toko kelontong, bahkan Pedagang Asongan sekalipun. Hal ini menandakan bahwa produk AMDK menjadi salah satu komoditas usaha yang menjanjikan. Dengan telah berkembangnya perusahaan AMDK, konsumen di beri banyak pilihan merek yang ada saat ini seperti Aqua, Ades, Club, Vit dll. Tak hanya itu, saat ini pun konsumen di beri kemudahan untuk memilih air mineral sesuai dengan kebutuhan.

Berdasarkan latar belakang tersebut maka peneliti berkeinginan untuk melakukan penelitian Pengaruh Green Marketing dan Brand Image Terhadap Minat Beli Merek AQUA Pada Mahasiswa S1 Fakultas Ekonomi dan Bisnis Universita Mataram. 


\section{Perumusan Masalah}

1. Apakah terdapat pengaruhgreen marketing terhadap minat beli konsumen pada produk AMDK merek AQUA?

2. Apakah terdapat pengaruh brand Image terhadap minat beli konsumen pada produk AMDK merek AQUA?

\section{Tujuan Penelitian}

1. Untukmenganalisispengaruh green marketing terhadap minat beli konsumen pada produk AMDK merek AQUA.

2. Untukmenganalisispengaruh brand Image terhadap minat beli konsumen pada produk AMDK merek AQUA.

\section{Kerangka Teoritis}

\section{Green Marketing}

Green marketingatau environment marketing itu berkembang sejalan dengan adanya perhatian masyarakat akan isu-isu lingkungan, sehingga masyarakat menuntut adanya tanggung jawab pelaku bisnis dalam melakukan aktivitas bisnis.Kepedulian pada lingkungan diintegrasikan pada strategi,kebijakan dan proses pada organisasi. Hal ini menuntunpengaruhaktivitas pemasaran pada lingkungan alami, juga mendorong praktekyang menghilangkan dan meminimalisasi efek yang merugikan. Filosofi dari pembangunan yang berkelanjutan menyediakan dorongan tambahan pada green marketing dengan menekankan bahwa perlindungan lingkungan bukan berarti menghilangkan kesejahteraan ekonomi, tetapi sebaliknya mendorong pemikiran kembali tentang bagaimana mengaitkan pemasaran dengan perlindungan lingkungan.

Pendekatan green marketing pada area produk meningkatkanintegrasi dari isu lingkungan pada seluruh aspek dari aktivitasperusahaan, mulai dari formulasi strategi, perencanaan, penyusunan, sampai produksi dan penyaluran/distribusi dengan pelanggan. Czinkota et al. (1992) mengatakan bahwa "perusahaan akandapat memperoleh solusi pada tantangan lingkunganmelalui strategi marketing, produk, dan pelayanan agar dapat tetap kompetitif'. Hal ini termasuk pada:

1. Teknologi baru untuk menangani limbah dan polusi udara,

2. Standarisasi produk untuk menjamin produk yang ramah lingkungan.

3. Menyediakan produk yang 'benar-benar' alami, dan

4. Orientasi produk lewat konservasi sumber daya dan yang lebih memperhatikan kesehatan.

Divekar (2015) menyatakan indicator Green Marketing antara lain Product, Price, Promotion dan Place.

Pengaruh Green Marketing dan Brand Image terhadap Minat Beli.

Dalam penelitian ini, peneliti menggunakan beberapa penelitian terdahulu. Almuarief (2016) menemukan bahwa Green marketing secara signifikan 
berpengaruhpositif terhadap brand image. Green marketing secara signifikan berpengaruh positif terhadap minat beli. Brand image secara signifikan berpengaruh positif terhadap minat beli. Selanjutnya Romadon dkk. (2014) membuktikan bahwa variabel green marketing berpengaruh signifikan terhadap variabel brandimage, variabel green marketing berpengaruh tidak signifikan terhadap variabel struktur keputusan pembelian dan variabel brand image berpengaruh signifikan terhadap variabel struktur keputusan pembelian. Risna dkk. (2015) menunjukkan bahwa variabel green marketing memiliki pengaruh langsung dan signifikan terhadap variabel minat beli. Variabel green marketing memiliki pengaruh langsung dan signifikan terhadap keputusan pembelian. Variabel minat beli memiliki pengaruh langsung dan signifikan terhadap keputusan pembelian.

\section{Pengembangan Hipotesis}

Berdasarkan Almuarief (2016) dan Yani dan Astuti (2016) menunjukan bahwa green marketing berpengaruh positif terhadap minat beli, maka:

\section{H1 : Green marketing berpengaruh positif terhadap minat beli.}

Defsinisi citra merek menurut Kotler dan Keller (2009) adalah persepsi yang dimiliki oleh konsumen saat pertama kali mendengar slogan yang diingat dan tertanam di benak konsumen. Kotler dan Keller juga menambahkan bahwa citra merek adalah persepsi dan keyakinan yang dipegang oleh konsumen, seperti yang dicerminkan asosiasi yang tertanam dalam ingatan konsumen. Beradasarkan penelitian yang di lakukan oleh Veronika (2016) dan Romadon (2014) hasil penelitian menunjukan brand image berpengaruh positif terhadap minat beli, maka:

\section{H2 : Brand image berpengaruh positif terhadap minat beli}

\section{Kerangka Konseptual}

Untuk mengetahui pemahaman mengenai variabel dalam penelitian ini, maka dibuat kerangka konseptual pemikiran sebagai berikut: 


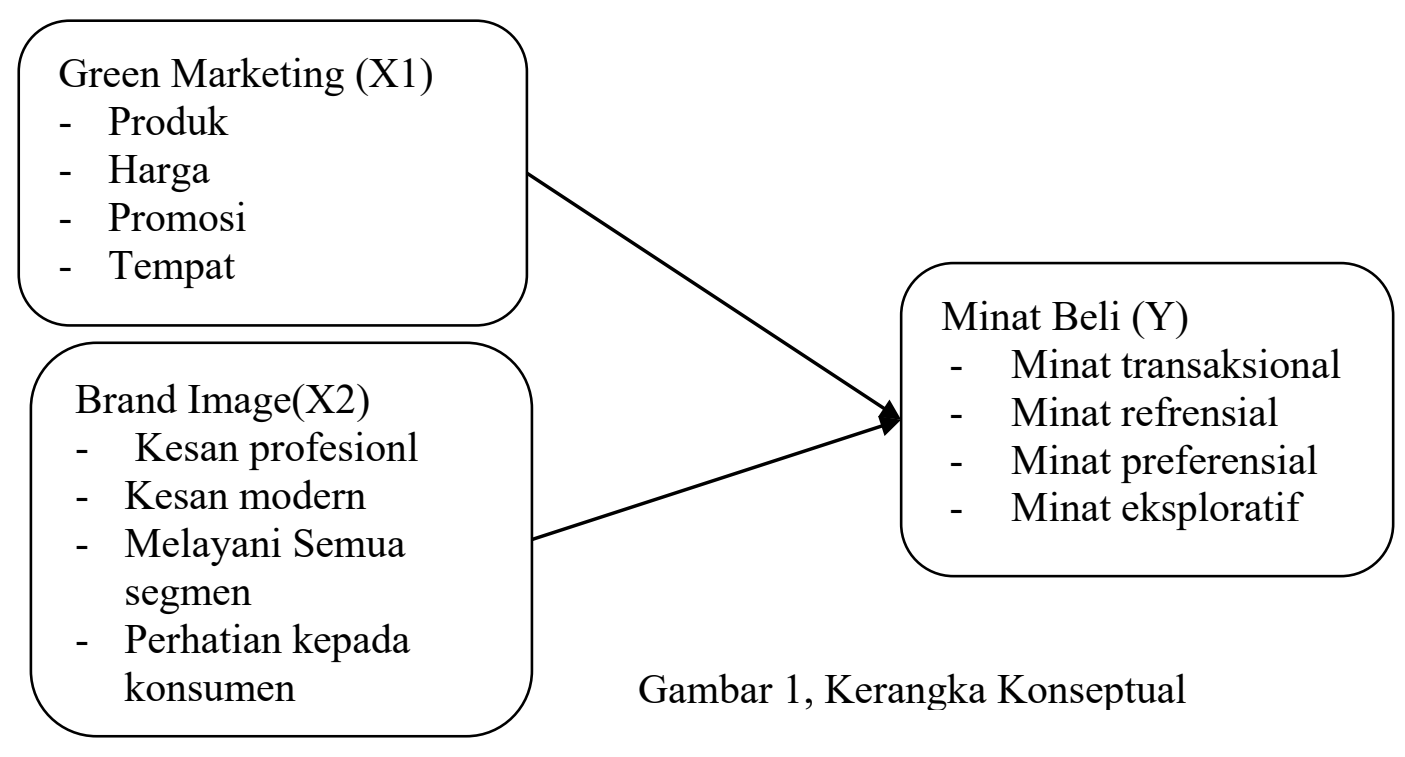

\section{METODE PENELITIAN}

\section{Jenis Penelitan}

Jenis penelitian ini merupakan jenis penelitian asosiatif. Penelitian ini adalah untuk menjelaskan dan meramalkan gejala yang ada pada objek penelitian yang diteliti (Sugiyono, 2010:11). Dalam penelitian ini peneliti ingin melihat pengaruh green marketing dan variabel dan brand image terhadap minat beli merek Aqua dikalangan Mahasiswa S1 Fakultas Ekonomi dan Bisnis Universitas Mataram.

\section{Lokasi}

Lokasi penelitian ini akan di lakukan di Fakultas Ekonomi dan Bisnis Universitas Mataram, alasannya adalah karena mahasiswa Fakultas Ekonomi dan Bisnis Universitas Mataram adalah generasi muda, terdidik, dan pemikir baru yang akan memperhatikanisu-isu lingkungan yang tengah diperbincangkan saat ini.

\section{Metode Pengumpulan Data}

Metode pengumpulan data yang digunakan dalam penelitian ini adalah metode sampelsurvey. Menurut Nazir (2005:217), sampel survey adalah suatu prosedur yang mana hanya sebagian dari populasi saja yang diambil untuk menentukan sampel yang diharapkan dapat mewakili populasi secara keseluruhan guna memperoleh gambaran yang cukup representatif.

\section{Penentuan Sampel dan Responden}

Dalam penelitian ini yang menjadi populasinya sebagai berikut 
Table 2. Jumlah populasi Mahasiswa S1 Fakultas Ekonomi dan Bisnis UniversitasMataram

\begin{tabular}{|c|l|l|}
\hline No & \multicolumn{1}{|c|}{ Semester } & \multicolumn{1}{c|}{ Populasi (orang) } \\
\hline 1 & I & 5.410 \\
\hline 2 & III & 5.312 \\
\hline 3 & V & 4.816 \\
\hline 4 & VII ke-atas & 4.615 \\
\hline Jumlah & 20.153 \\
\hline
\end{tabular}

Sumber: FEB Universitas Mataram 2017(diolah).

Dari data di atas kita dapat melihat jumah populasi mahasiswa fakultas ekonomi dan bisnis universitas mataram dengan perwakilan per semesternya yaitu : semester 1 sebanyak 5.410 semester III sebanyak 5.312 semester V 4.816 semester VII ke-atas sebanyak 4.615 dengan populasi tersebut diambil sesuai semester ganjil, karna penelitian dilakukan pada saat semester ganjil berlangsung.

\section{Sampel}

Sampel merupakan bagian dari populasi yang diambil melalui cara-cara tertentu yang juga memiliki krakteristik tertentu, jelas, dan lengkap yang dianggap bias mewakili populasi (Ferdinand,2006). Penentuan jumlah sampel dalam penelitian ini di lakukan dengan menggunakan rumus sebagai berikut:

$$
\mathrm{n}=\frac{\mathrm{N}}{1+\mathrm{N}(\mathrm{e})^{2}}
$$

dimana:

$\mathrm{n} \quad=$ Jumlah sampel

$\mathrm{N}=$ Jumlah populasi

$\mathrm{e}=$ Presentasi kesalahan pengambilan sampel (dalam penelitian ini sebesar $10 \%$ atau $0,1)$

$\mathrm{n}=\frac{20153}{1+20153(0,1)^{2}}$

$\mathrm{n}=99$

Berdasarkan perhitungan tersebut maka jumlah sampel yang ditetapkan dalam penelitian ini adalah sebesar 99 responden yang dibulatkan menjadi 100 responden. Untuk menentukan besarnya sampel pada masing-masing lokasi penelitian menggunakan proportional karena datanya hetrogen dan terdiri dari beberapa kelompok (Riduwan,2005:66), dengan menggunakan rumus:

$$
\mathrm{nsi}=\left[\frac{N i}{N} \times n\right]
$$


Dengan:

nsi $=$ Jumlah sampel dari setiap semester

$\mathrm{Ni}=$ Populasi per-semester

$\mathrm{N}=$ jumlah populasi

$\mathrm{N}=$ Jumlah sampel

Rincian jumlah responden di masing-masing semester sebagai berikut:

$\begin{array}{ll}\text { Semester I } & =\frac{5410}{20153} \times 100=26 \\ \text { Semester III } & =\frac{5312}{20153} \times 100=26 \\ \text { Semester V } & =\frac{4816}{20153} \times 100=24 \\ \text { Semester VII ke-atas } & =\frac{4615}{20153} \times 100=23\end{array}$

Pengambilaan sampel akhir dari masing-masing semester menggunakan teknik sistematik random sampling. Karena daftar dari seluruh populasi berikut nomer urutnya telah tersedia. Pengambilan dengan sampel nomersatu dilakukan dengan cara lotere atau bilangan random sedang bilangan ke dua dan seterusnya ditentukan secara sistematik yaitu meloncat nomer berikut sesuai dengan jarak tertentu (Riduwan,2005:72).

\section{Teknik Pengumpulan Data}

Dalam penelitian ini yang akan dilakukan teknik pengumpulan data Angket yakni serupa daftar pertanyaan yang disebarkan kepada responden dan diberi tanggapan oleh responden mengenai variabel-varibel yang akan di teliti. Dalam penelitian ini penulis akan memberikan lembar pertanyaan mengenai variabel-variabel yaang berkaitan dengan masalah yang di teliti.

\section{Alat Pengumpulan Data}

Alat pengumpulan data yang digunakan dalam penelitian ini adalah kuesioner. Kuesioner adalah daftar pertanyaan yang di sebarkan kepada responden untuk diisi dan diberikan jawaban atas pertanyaan-pertanyaan tersebut.

\section{Jenis Data}

Jenis data yang digunakan dalam penelitian ini adalah data kuantitatif. Data kuantitatif adalah data yang berupa angka-angka yang dapat dihitung dan diukur. Data kuantitatif ini berasal dari jawaban angket yang diberi skor kemudian dihitung dengan alat analisis yang digunakan.

\section{Sumber Data}

Sumber data yang digunakan dalam penelitian ini adalah data primer dan data sekunder. 


\section{Analisis Data}

Solusi Pemecahan permasalahan penelitian ini dilakukan dengan analisis regersi linier berganda dengan bantuan aplikasi SPSS 16.

\section{HASIL DAN PEMBAHASAN}

\section{Uji Asumsi Klasik}

Asumsi klasik yang dilakukan yaitu normalitas, multikolinieritas dan heteroskedastisitas. Berikut penjelasan hasil uji asumsi klasik yang dimaksud.

\section{Uji Normalitas}

Berikut hasil uji normalitasdapat dilihat pada tabel dibawah ini:

Tabel 3. Hasil Uji Normalitas Kolmogorov-Smirnov

\begin{tabular}{|c|c|c|}
\hline & & Unstandardized Residual \\
\hline \multicolumn{2}{|l|}{$\mathrm{N}$} & 100 \\
\hline \multirow{2}{*}{\begin{tabular}{|l|} 
Normal \\
Parameters $^{\mathrm{a}}$
\end{tabular}} & Mean & .0000000 \\
\hline & Std. Deviation & 3.54734957 \\
\hline \multirow{3}{*}{$\begin{array}{l}\text { Most Extreme } \\
\text { Differences }\end{array}$} & Absolute & .077 \\
\hline & Positive & .074 \\
\hline & Negative & -.077 \\
\hline \multicolumn{2}{|c|}{ Kolmogorov-Smirnov Z } & .766 \\
\hline \multicolumn{2}{|c|}{ Asymp. Sig. (2-tailed) } & .600 \\
\hline \multicolumn{2}{|c|}{ a. Test distribution is Normal. } & \\
\hline
\end{tabular}

Sumber: lampiran7 (diolah menggunakan SPSS16)

Tabel 3tersebut menunjukan bahwa nilai sig $>5 \%(0,05)$ atau $(0,600>0,05)$ sehingga dapat diartikan bahwa data tersebutberdistribusi normal, dengan demikian pegujian selanjutnya dapat dilakukan.

\section{Uji Multikolonieritas}

Uji multikolinieritas bertujuan untuk menguji apakah pada model regresi ditemukan adanya korelasi antara variabel bebas. Menurut Ghozali (2007:91) model regresi yang baik seharusnya tidak terjadi korelasi diantara variabel bebas. Ada beberapa cara untuk menguji ada atau tidaknya multikolinieritas dalam model regresi yaitu dengan menggunakan analisis matrik korelasi antara variabel bebas dengan melihat nilai variance inflation factor (VIF). Jika nilai tolerance $>0,10$ atau sama dengan VIF $<10$, maka berarti tidak terjadi multikolinieritas dalam model regresi. 
Adapun hasil pengujian Multikolinieritas adalah sebagai berikut:

Tabel 4, Hasil Uji Mutikolinieritas

\begin{tabular}{|c|c|c|c|c|c|c|c|c|}
\hline & \multirow[t]{2}{*}{ Model } & \multicolumn{2}{|c|}{$\begin{array}{c}\text { Unstandardized } \\
\text { Coefficients }\end{array}$} & \multirow{2}{*}{$\begin{array}{c}\begin{array}{c}\text { Standardized } \\
\text { Coefficients }\end{array} \\
\text { Beta } \\
\end{array}$} & \multirow[t]{2}{*}{$\mathbf{T}$} & \multirow[t]{2}{*}{ Sig. } & \multicolumn{2}{|c|}{ Collinearity Statistics } \\
\hline & & B & Std. Error & & & & Tolerance & VIF \\
\hline \multirow[t]{3}{*}{1} & (Constant) & 20.553 & 3.425 & & 6.002 & .000 & & \\
\hline & $\begin{array}{l}\text { Green } \\
\text { Marketing }\end{array}$ & .376 & .072 & .520 & 5.219 & .000 & 1.000 & 1.000 \\
\hline & Brand Image & -.127 & .097 & -.131 & -1.311 & .194 & 1.000 & 1.000 \\
\hline
\end{tabular}

Sumber: data diolah menggunakan SPSS16

Tabel 4.8 di atas menunjukan bahwa nilai tolerance dari green marketing (X1) dan brand image (X2) lebih besar dari 0,10 atau $1.000>0,10$ dan nilai VIF dari green marketing (X1) dan brand image (X2) lebih kecil dari 10 atau $10<1.000$ Hal ini berarti bahwa tidak terjadi multikolinieritas dalam model regresi ini, maka tidak ada korelasi diantara variabel bebas yang digunakan dalam penelitian ini.

\section{Uji heteroskedastisitas}

Uji heteroskedastisitas bertujuan untuk menguji apakah dalam model regresi terjadi ketidaksamaan varian dari residual satu pengamatan ke pengamatan yang lain (Ghozali, 2007:87). Jika varian dari residual satu spengamatan ke pengamatan yang lain tetap, maka disebut homoskedastisitas dan jika berbeda disebut heteroskedastisitas. Model regresi yang baik adalah yang tidak menghasilkan heteroskedastisitas, dimana salah satu cara yang dapat digunakan adalah dengan uji glejser. Dasar pengambilan keputusannya adalah tidak terjadi heteroskedastisitas jika nilai $\mathrm{t}$ - hitung dari $\mathrm{t}$ - tabel dan nilai signifikansi $>0,05$ dan begitu sebaliknya. Hasil uji heteroskedastisitas dibawah ini:

Tabel 5. Hasil Uji Heteroskedastisitas

\begin{tabular}{|c|c|c|c|c|c|}
\hline \multirow[b]{2}{*}{ Model } & \multicolumn{2}{|c|}{$\begin{array}{c}\text { Unstandardized } \\
\text { Coefficients }\end{array}$} & \multirow{2}{*}{$\begin{array}{c}\text { Standardized } \\
\text { Coefficients } \\
\text { Beta } \\
\end{array}$} & \multirow[b]{2}{*}{$\mathrm{T}$} & \multirow[b]{2}{*}{ Sig. } \\
\hline & $\mathrm{B}$ & Std. Error & & & \\
\hline (Constant) & 2.934 & 1.868 & & 1.571 & .120 \\
\hline green marketing & .019 & .043 & .045 & .448 & .655 \\
\hline brand image & -.016 & .053 & -.032 & -.311 & .756 \\
\hline
\end{tabular}

Sumber: Data diolah menggunakan SPSS 16

Tabel 4.9 di atas menunjukan bahwa nilai signifikansi green marketing (X1) dan lebih besar dari 0,05 atau $0,655>0,05$ dan nilai signifikansi variabel brand image (X2) juga lebih besar dari 0,5 atau 0,756>0,05, maka dapat disimpulkan bahwa tidak terjadi heteroskedastisitas diantara variabel-variabel penelitian. 


\section{Analisis Regresi Linier Berganda}

Hasil dari analisis regresi linier berganda bisa dilihat di bawah ini:

Tabel 6. Hasil Analisis Regresi Linier Berganda

\begin{tabular}{|c|c|c|c|c|c|c|}
\hline & \multirow[t]{2}{*}{ Model } & \multicolumn{2}{|c|}{$\begin{array}{c}\text { Unstandardized } \\
\text { Coefficients }\end{array}$} & \multirow{2}{*}{$\begin{array}{c}\text { Standardized } \\
\text { Coefficients } \\
\text { Beta }\end{array}$} & \multirow[t]{2}{*}{$\mathrm{T}$} & \multirow[t]{2}{*}{ Sig. } \\
\hline & & $\mathrm{B}$ & Std. Error & & & \\
\hline \multirow[t]{3}{*}{1} & (Constant) & 17.967 & 3.493 & & 5.144 & .000 \\
\hline & green marketing & .293 & .080 & .350 & 3.670 & .000 \\
\hline & brand image & -.003 & .099 & -.003 & -.033 & .974 \\
\hline \multicolumn{3}{|c|}{ a. Dependent Variable: minat beli } & & & & \\
\hline
\end{tabular}

Sumber: lampiran 10 (diolah menggunakan SPSS16)

Berdasarkan Tabel 4.10 di atas dapat disusun persamaan regresi linier bergandanya, yaitu: $\mathbf{Y}=\mathbf{1 7 . 9 6 7}+\mathbf{0 . 3 5 0 X 1} \mathbf{- 0 . 0 0 3 X 2}+$ e. Maka dari hasil perhitungan menggunakan SPSS V.16 pada tabel di atas dapat interpretasikan sebagai berikut:

Pengaruh variabel Green Marketing ( $\left.\mathrm{X}_{1}\right)$ terhadap Minat Beli (Y). Berdasarkan perhitungan dengan program SPSS 16, diperoleh nilai koefisien regresi sebesar 0,350, nilai t Hitung sebesar 3.670 dan t Tabel sebesar 2,276 dengan nilai signifikansi 0,000. Apabila nilai t Hitung sebesar 3,670 dibandingkan dengan nilai t Tabel sebesar 2,276 maka nilai t Hitung tersebut lebih besar dari pada t Tabel yang berarti Ho ditolak dan Ha diterima. Hal ini juga dapat dilihat dari nilai perbandingan antara nilai signifikan yang dicapai sebesar 0,000 yang berarti tingkat kesalahan lebih kecil dari 0,05 (5\%). Dengan demikian Green marketing (X1) memiliki pengaruh yang positif dan signifikan terhadap Minat Beli (Y).

Pengaruh variabel Brand Image $\left(\mathrm{X}_{1}\right)$ terhadap Minat Beli $(\mathrm{Y})$. Berdasarkan perhitungan dengan program SPSS 16, diperoleh nilai koefisien regresi sebesar 0,350, nilai t Hitung sebesar 0,033 dan nilai t Tabel sebesar 2,276. Dengan nilai signifikansi 0,974. Apabila nilai t Hitung sebesar 0,033 dibandingkan dengan nilai t Tabel sebesar 2,276, maka nilai t Hitung tersebut lebih kecil dari pada $t$ Tabel yang berarti Ha ditolak dan Ho diterima. Hal ini juga dapat dilihat dari nilai perbandingan antara nilai signifikan yang dicapai sebesar 0,173 yang berarti tingkat kesalahan lebih besar dari $0,05(5 \%)$. Dengan demikian variabel brand image (X2) memiliki pengaruh yang negative dan tidak signifikan terhadap Minat Beli (Y). 


\section{PEMBAHASAN}

\section{Pengaruh Green Marketing Terhadap Minat Beli AMDK Merek Aqua.}

Hipotesa yang menyatakan bahwa "green marketing berpengaruh positif terhadap minat beli Amdk merek Aqua dikalangan Mahasiswa S1 fakultas Ekonomi dan Bisnis Universitas Mataram" Terbukti. Karna hasil statistik Pada uji hipotesis diperoleh $\mathrm{t}$ hitung sebesar $3.670>\mathrm{t}$ tabel 2.276 dengan nilai signifikansi sebesar $0.000<0.05$. Ini menunjukkan bahwa variabel green marketing (X1) berpengaruh positif dan signifikan terhadap variabel minat beli (Y). selain itu berdasarkan pengamatan peneliti, kosumen cukup setuju dengan produk Aqua yang memiliki kemasan yang ramah ingkungan sehingga meminimalkan penggunaan plastic yang berbahaya bagi lingkungan. Hal ini berarti green marketing berpengaruh postif terhadap minat beli Amdk merek Aqua dikalangan Mahasiswa S1 Fakultas Ekonomi dan Bisnis Universitas Mataram.

Hal ini berbeda dengan penelitian sebelumnya yang telah dilakukan oleh Risma, dkk. (2015). Yang menunjukan bahwan green marketing berpengaruh langsung dan signifikan terhadap minat beli. Adapun hal lain yang membuatnya berbeda yakni terletak pada perbedaan indikator dan objek penelitian yang digunakan, dimana objek penelitiannya lebih besar dibandingkan dengan Mahasiswa S1 Fakultas Ekonomi Universitas Mataram.

\section{Pengaruh Brand Image Terhadap Minat Beli AMDK Merek Aqua}

Hipotesa yang menyatakan bahwa "Brand Image berpengaruh positif terhadap minat beli Amdk merek Aqua dikalangan Mahasiswa S1 fakultas Ekonomi dan Bisnis Universitas Mataram" Tidak Terbukti. Karna hasil statistik Pada uji hipotesis diperoleh $\mathrm{t}$ hitung sebesar $-0.003>\mathrm{t}$ tabel 2.276 dengan nilai signifikansi sebesar 0.974 $>0.05$. Ini menunjukkan bahwa variabel Brand Image (X2) berpengaruh negative terhadap variabel minat beli (Y). Kosumen kurang setuju dengan produk Aqua yang dapat diterima oleh semua segmen. Hal ini berarti brand image berpengaruh negative terhadap minat beli Amdk merek Aqua dikalangan Mahasiswa S1 Fakultas Ekonomi dan Bisnis Universitas Mataram.

Hal ini berbeda dengan penelitian sebelumnya yang telah dilakukan Almuarif (2016). Yang menunjukan bahwan brand image berpengaruh positif dan signifikan terhadap minat beli. Adapun hal lain yang membuatnya berbeda yakni terletak pada perbedaan indikator dan objek penelitian yang digunakan, dimana objek penelitiannya lebih besar dibandingkan dengan Mahasiswa S1 Fakultas Ekonomi Universitas Mataram 


\section{KESIMPULAN}

Berdasarkan hasil pembahasan maka dapat ditarik kesimpulan sebagai berikut:

1. Berdasarkan hasil penelelitian ini bahwa dari Variabel Green marketing memiliki pengaruh positif terhadap minat beli, yang menunjukan konsumen sudah paham tentang kelestarian lingkungan.

2. Variabel Brand Image tidak memiliki pengaruh terhadap minat beli, artinya ada faktor lain yang diperhatikan konsumen dalam melakukan pembelian misalnya harga.

\section{DAFTAR PUSTAKA}

Almuarief (2016). Pengaruh green marketing terhadap minat beli yang dimediasi oleh Brand image. Jurnal Manajemen Pemasaran. Diunduh pada

Czinkota, M.R., Rivoli, P and Ronkainen, IA. (1992). International Business Enterprises, 7th Edition, Dryden Press.

Ferdinand, A. 2006, Metode Penelitian Manajemen: Pedoman Penelitian untuk. Skripsi, Tesis dan Disertasi Ilmu Manajemen, Semarang: Badan Penerbit. Universitas Diponegoro.

Ghozali, I. 2007. Analisis Multivariate Dengan Program SPSS. Cetakan Empat. Badan. Penerbit Universitas diponegoro. Semarang.

Kotler, P. dan Keller. 2009. Manajemen Pemasaran. Jilid I. Edisi ke 13 Jakarta: Erlangga.

Nazir, M.2005. Metode Penelitian. Jakarta: Ghalia Indonesia.

Risna, DA., Kumadji, S dan Yulianto, E, (2015). Pengaruh G r e e $\mathrm{n}$ $\mathrm{M}$ a $\mathrm{r}$ k e $\mathrm{t}$ i $\mathrm{n} \mathrm{g}$ terhadap minat beli serta dampaknya pada keputusan pembelian (survei pada konsumen non-member tupperware di kota malang) Jurnal administrasi bisnis (JAB) vol. 22 no. 2, 1-10

Riduwan (2005). Dasar-Dasar Statistika Keuangan. Bandung: Alfabeta.

Romadon, Y, Kumadji, S. dan Abdilah, Y. (2014) Pengaruh Green Marketing Terhadap Brand Image Dan Struktur Keputusan Pembelian, Jurnal Administrasi Bisnis (JAB) $\mid$ Vol. 15 No. 1 Oktober, 1-7.

Sugiyono.2010. Metode Penelitian Pendidikan Pendekatan Kuantitatif, kualitatif, dan R\&D. Bandung: Alfabeta.

Yani, M. Dan Astuti, M. (2016). Pengaruh green marketing, lingkungan dan kesehatan terhadap keputusan pembelian melalui minat membeli produk organik (studi pada hero supermarket sidoarjo). In: seminar nasional ekonomi bisnis 2016, 17 september 2016, universitas muhammadiyah sidoarjo. 